\title{
IL-21-dependent expansion of memory-like NK cells enhances protective immune responses against Mycobacterium tuberculosis
}

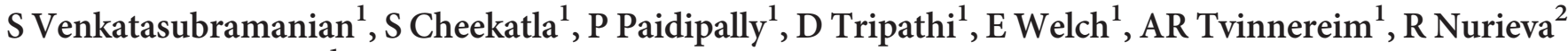 \\ and R Vankayalapati ${ }^{1}$
}

Natural killer (NK) cells are traditionally considered as innate cells, but recent studies suggest that NK cells can distinguish antigens, and that memory NK cells expand and protect against viral pathogens. Limited information is available about the mechanisms involved in memory-like NK cell expansion, and their role in bacterial infections and vaccine-induced protective immune responses. In the current study, using a mouse model of tuberculosis (TB) infection, we found that interferon-gamma producing CD3 - NKp46 + CD27 + KLRG1 + memory-like NK cells develop during Bacille Calmette-Guérin vaccination, expand, and provide protection against challenge with Mycobacterium tuberculosis (M. tb). Using antibodies, short interfering RNA and gene-deleted mice, we found that expansion of memory-like NK cells depends on interleukin 21 (IL-21). NKp46 + CD27 + KLRG1 + NK cells expanded in healthy individuals with latent TB infection in an IL-21-dependent manner. Our study provides first evidence that memory-like NK cells survive long term, expansion depends on IL-21, and involved in vaccine-induced protective immunity against a bacterial pathogen.

\section{INTRODUCTION}

Mycobacterium tuberculosis (M. tb) causes almost 1.3 million deaths yearly. ${ }^{1}$ Of the one-third of household contacts of tuberculosis (TB) patients who develop latent tuberculosis infection (LTBI), most remain healthy, but $10 \%$ may develop $\mathrm{TB}^{2}$ Control of $M$. $t b$ infection requires cooperation of the innate and adaptive immune systems. Several studies demonstrated the crucial role of $\mathrm{T}$ cells in protective immunity against M. $t b,{ }^{3}$ mediated in part through the production of interferongamma (IFN- $\gamma$ ), which is required for resistance to infection. ${ }^{4}$ Limited information is available about the role of innate immunity in $M$. $t b$ infection. Harnessing these innate immune mechanisms is critical to combat the global surge in multidrugresistant $\mathrm{TB}$, which responds suboptimal to treatment, despite lengthy expensive and toxic regimens.

Natural killer (NK) cells are prominent components of the innate immune system that have a central role in resistance to microbial pathogens. NK cells protect against viruses, bacteria, and parasites through the destruction of infected cells and secretion of cytokines that shape the adaptive immune response. ${ }^{5}$ We found that human NK cells lyse $M$. $t b$-infected monocytes and alveolar macrophages, and upregulate CD8 + T-cell responses. ${ }^{6,7} \mathrm{NK}$ cells lyse $M$. $t$-expanded T-regulatory cells, ${ }^{8}$ and eliminating NK cells at the time of Bacille CalmetteGuérin (BCG) vaccination enhances expansion of T-regulatory cells and inhibits BCG-induced protection against challenge with $M$. $t b .{ }^{9}$ Human NK cells also produce IFN- $\gamma$ when exposed to $\mathrm{BCG},{ }^{10}$ and the pleural fluid of TB patients is enriched for $\mathrm{CD} 56^{\text {bright }} \mathrm{CD} 16$ - NK cells, which are the predominant source of IFN- $\gamma .^{11}$

Recent studies have found antigen-specific memory NK cells, ${ }^{12}$ homeostatic proliferation of long-lived NK cells, ${ }^{13}$ and expansion of a unique CD57 + NKG2C ${ }^{\text {hi }} \mathrm{NK}$ cell subset and KLRG1 + memory-like NK cells in viral infections. ${ }^{14}$ Further studies suggest that pro-inflammatory cytokine signaling is required for the generation of NK cell memory. ${ }^{15}$ In the current

${ }^{1}$ Department of Pulmonary Immunology, Center for Biomedical Research, University of Texas Health Science Center at Tyler, Tyler, Texas, USA and ${ }^{2}$ Department of Immunology, M. D. Anderson Cancer Center, Houston, Texas, USA. Correspondence: R Vankayalapati (krishna.vankayalapati@uthct.edu) 


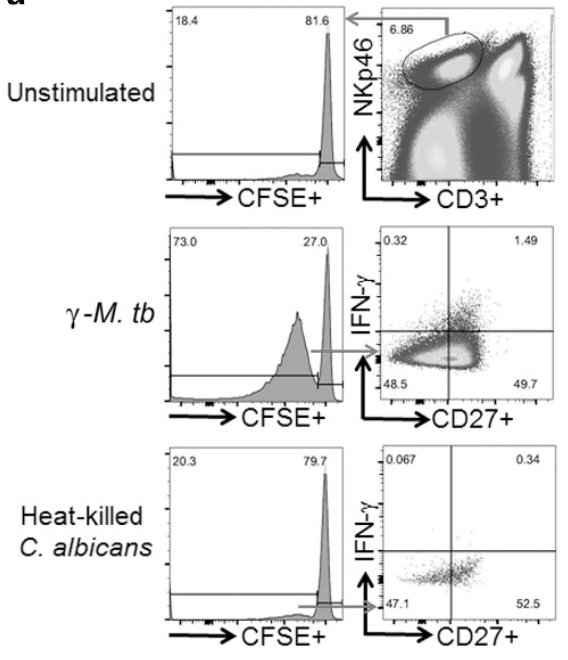

b
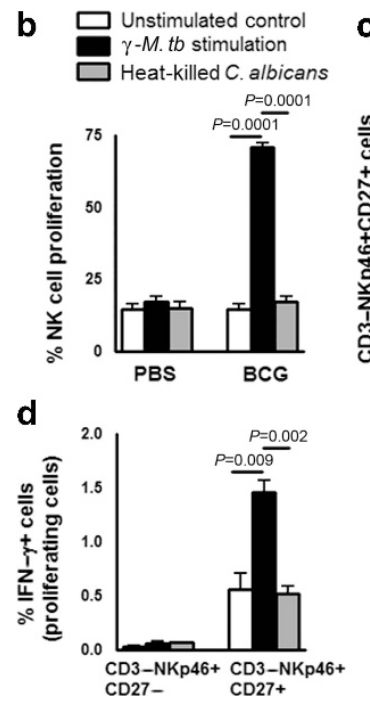

C

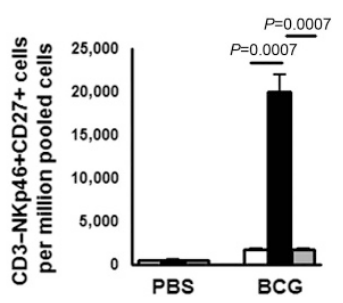

Figure 1 Bacille Calmette-Guérin (BCG) vaccination induces the expansion of memory-like natural killer (NK) cells. (a, b) C57BL/6 mice (five mice per group) were given $100 \mu \mathrm{l}$ of phosphate-buffered saline (PBS; unimmunized) or immunized subcutaneously with $10^{6}$ colony-forming unit of BCG in $100 \mu$ l of PBS. Six months after vaccination, spleen and peripheral lymph node cells were isolated, pooled, labeled with carboxyfluorescein succinimidyl ester (CFSE), and cultured, with or without $\gamma-M$. tb or heat-killed Candida albicans. After 5 days, expanding CD3 - NKp46 + CD27 + NK cells and interferongamma (IFN- $\gamma$ )-producing cells were measured by flow cytometry. (a) A representative flow cytometry plot is shown (BCG vaccinated mice). NK cells were identified by sequentially gating on singlet population and then on CD3 - NKp46 + NK cells. The events within the gated CD3 - NKp46 + NK cells were analyzed for CFSE + cells and plotted in the histograms. Total lung CFSE + CD3 - NKp46 + CD27 + NK cell numbers are shown. (b) Percent proliferating NK cells (c) Absolute number of CD3 - NKp46 + CD27 + cells. (d) CD3 - NKp46 + CD27 - IFN- $\gamma+$, and CD3 - NKp46 + CD27 + IFN- $\gamma+$ cells. Mean values and s.e.'s are shown. Data are representative of two independent experiments.

study, using a mouse model and cells from persons infected with $M$. $t b$, we identified memory-like NK cells and the factors that regulate their expansion. We found that memory-like NK cells contribute to vaccine-induced protective immune responses against $M . t b$ infection and IL-21 mediates the development and expansion of memory-like NK cells.

\section{RESULTS}

Expansion of memory-like NK cells in BCG-vaccinated mice To determine whether memory-like NK cells expand after vaccination with mycobacteria, we treated wild-type C57BL/6 mice with PBS or vaccinated subcutaneously with $10^{6}$ colonyforming unit (CFU) of BCG. One month after vaccination, spleen and peripheral lymph node cells were isolated, pooled, and cultured, with or without Ag85 or $\gamma$-irradiated M. $t b \mathrm{H} 37 \mathrm{Rv}$ $(\gamma-M . t b)$. After 5 days, we determined the expansion of $\mathrm{CD} 3-\mathrm{NKp} 46+\mathrm{NK}$ cells expressing DNAM1, CD27, NKG2D, KLRG1, and CD62L. In BCG-vaccinated mice, among all the markers tested, only CD3 - NKp46 + CD27 + cells expanded from $1,444 \pm 271.9$ to $31,050 \pm 4,005$ cells per $10^{6}$ pooled cells $(P=0.001$, Supplementary Figure S1A online). The above experiment was performed 1 month after vaccination and it is possible that activated NK cells may be expanding non-specifically in response to antigen.

We performed the above experiment 3 months after BCG vaccination. We measured live BCG in lungs and various lymphoid organs 3 months after vaccination and were not able to detect any live BCG (data not shown). In BCG-vaccinated mice, $\mathrm{CD} 3-\mathrm{NKp} 46+\mathrm{CD} 27+$ cells expanded from
$1,444 \pm 271.9$ to $27,380 \pm 3,917$ cells per $10^{6}$ pooled cells $(P=0.002$, Supplementary Figure S1B $)$. We further characterized the expanding CD3 - NKp46 + CD27 + cells using various cell surface markers for NK cell receptors. Among various markers tested 1 month after BCG vaccination, only CD3 - NKp46 + CD27 + KLRG1 + cells expanded from $1,135 \pm 304.1$ to $2,523 \pm 690.2$ cells per $10^{6}$ pooled cells $(P=0.04$, Supplementary Figure S1C) upon Ag85 stimulation. In contrast, CD3 - NKp46 + CD27 + KLRG1 + cells did not expand in PBS-treated mice (Supplementary Figure S1C). Three months after BCG vaccination, similar expansion of CD3 - NKp46+CD27 + KLRG1 + cells was noted upon Ag85 stimulation (Supplementary Figure S1D).

The above results suggest expansion of a subpopulation of NK cells in BCG-vaccinated mice upon Ag85 or $\gamma-M$. $t b$ stimulation. We determined the antigen specificity and proliferative capacity of expanding memory-like CD3$\mathrm{NKp} 46+\mathrm{CD} 27+$ cells. Six months after BCG vaccination or PBS treatment, spleen and peripheral lymph node cells were isolated, pooled, labeled with carboxyfluorescein succinimidyl ester (CFSE), and cultured, with or without $\gamma-M$. $t b$ or heat-killed Candida albicans and determined the expansion of CD3 - NKp46+CD27 + NK cells (Figure 1a and $\mathbf{b}$ ). In BCG-vaccinated mice, upon stimulation with $\gamma-M$. $t b$, the proliferating CD3 - NKp46 + CD27 + cells expanded from $1,777 \pm 101.9$ to $20,050 \pm 1,918$ cells per $10^{6}$ pooled cells $(P=0.0007$, Figure 1c). In contrast, CD3 - NKp $46+\mathrm{CD} 27+$ cells unable to expand upon heat-killed Candida albicans stimulation. In $\gamma-M$. $t b$-stimulated cells, IFN- $\gamma+\mathrm{CD} 3-$ 

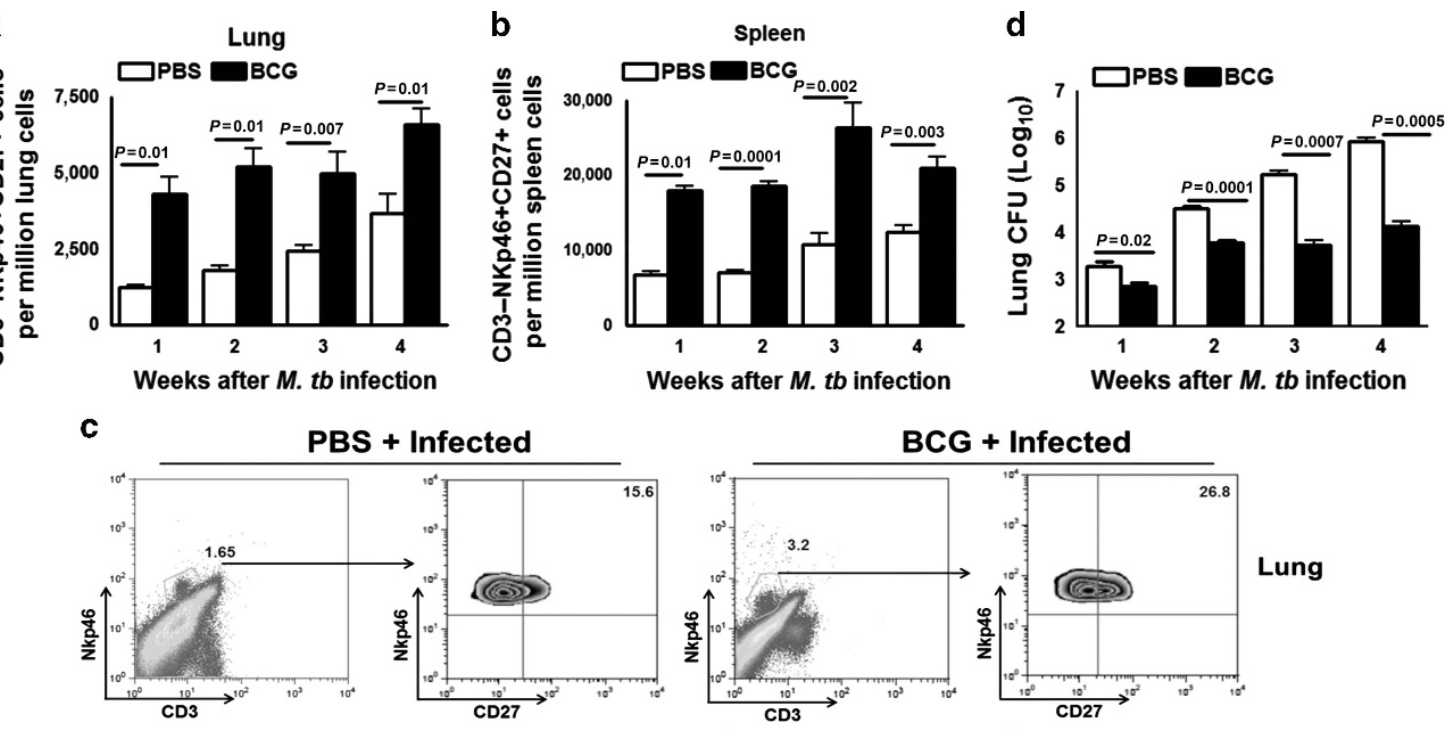

CG + Infected
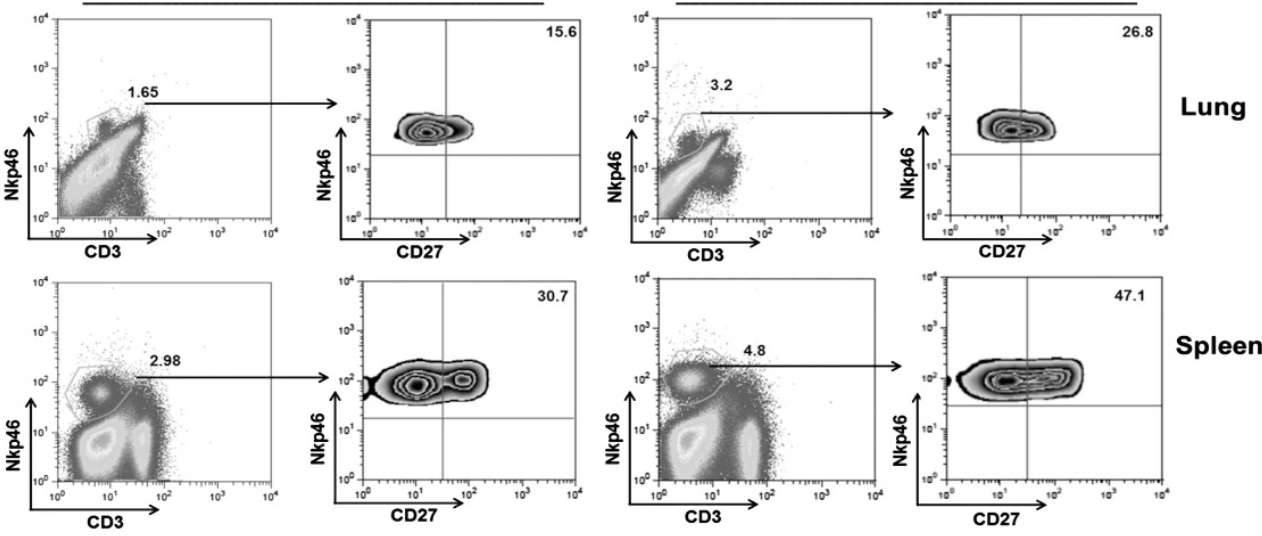

Week 3 after $M$. tb infection

Figure 2 Memory-like natural killer (NK) cells expand after Bacille Calmette-Guérin (BCG) vaccination and challenge with M. tb H37Rv. C57BL/6 mice (20 mice per group) were given $100 \mu \mathrm{l}$ of phosphate-buffered saline (PBS) or immunized subcutaneously with $10^{6}$ colony-forming unit (CFU) of BCG in $100 \mu \mathrm{l}$ of PBS. After 30 days, mice were challenged with 75-100 CFU of M. tb H37Rv by aerosol. At weekly intervals up to 4 weeks, five mice in each group were killed, and the lung bacterial burden and percentages of CD3 - NKp46 + cells in lungs and spleen that were CD27 + were determined. (a) CD3 - NKp46 + CD27 + cells in lungs. (b) CD3 - NKp46 + CD27 + cells in spleens. (c) A representative flow cytometry plot is shown. Gating strategy to identify NK cells was similar to Figure 1. (d) Bacterial burden in lungs. Mean values and s.e.'s are shown. Data are representative of two independent experiments.

$\mathrm{NKp} 46+\mathrm{CD} 27+$ cells (gated on proliferating cells) were threefold higher compared with IFN- $\gamma+\mathrm{CD} 3-\mathrm{NKp} 46+$ CD27 - cells $(P=0.009$, Figure 1d). In PBS-treated mice, $\gamma-M . t b$ or heat-killed Candida albicans unable to expand IFN- $\gamma+\mathrm{CD} 3-\mathrm{NKp} 46+\mathrm{CD} 27+$ cells (Figure 1d).

\section{Memory-like NK cells expand during $\boldsymbol{M}$. tb Infection}

To determine whether the expansion of CD3 - NKp46+ $\mathrm{CD} 27$ + cells correlates with decreased bacterial burden in $M$. $t b$-infected mice, we treated mice subcutaneously with PBS or immunized them with BCG. After 1 month, mice were infected by aerosol challenge with $M$. $t b \mathrm{H} 37 \mathrm{Rv}$. We measured CD3 - NKp46 + CD27 + cells in lungs and spleens, as well as bacterial burden in lungs every 7 day until 1 month. As shown in Figure 2a, b and c, 1 week after challenge with $M$. tb H37Rv, there is a significant difference in the proportion of CD3 - NKp46 + CD27 + cells in lungs and spleen of BCGvaccinated, compared with PBS-treated mice. These differences persisted in the lungs at least 4 weeks after $M$. $t b$ infection (Figure 2a, b and c) and fold changes were shown in Supplementary Figure S2. The bacterial burden was significantly higher in the lungs of PBS-treated than BCG-vaccinated mice 1 week after infection, and these differences widened to a 2-log by 4 weeks after infection (Figure 2d).

\section{Memory-like NK cells proliferate and produce IFN- $\gamma$ in M. tb-infected mice}

We determined whether memory-like NK cells (CD3$\mathrm{NKp} 46+\mathrm{CD} 27+$ and $\mathrm{CD} 3-\mathrm{NKp} 46+\mathrm{CD} 27+\mathrm{KLRG} 1+$ ) proliferate and produce IFN- $\gamma$ upon adoptive transfer to $M$. $t b$-infected recipient mice. CD57BL/6 (CD45.2 congenic) mice were vaccinated with BCG or treated with PBS. After 6 month, cells were pooled from the spleen and lymph nodes, and $\mathrm{CD} 3-\mathrm{NKp} 46+\mathrm{CD} 27+\mathrm{NK}$ cells were isolated and adoptively transferred to naive C57BL/6 mice expressing congenic marker CD45.1 (Figure 3a). As shown in Figure 3b and c, 10 days after adoptive transfer, $192.3 \pm 80.76$ cells per million lung cells were CD45.2 NK cells (CD3 - NKp46 + CD27 +). Ten days after adoptive transfer, recipient mice were infected with M. $t b$ H37Rv. Fifteen days after infection, the numbers of CD45.2 NK cells (adoptively transferred NKp46 + CD3 CD27 + cells from BCG-vaccinated mice) were $3.7 \pm 0.6 \%$ $(32,000 \pm 1,799$ vs. $2,590 \pm 236.3$ cells per million lung cells, 12 -fold increase compared with CD45.2 NK cells from PBS-treated mice, $P=0.0001$, Figure $3 \mathbf{c}$ and $\mathbf{d}$ ), and out of these, $14.4 \pm 1.2 \%$ of CD $45.2+\mathrm{NKp} 46+\mathrm{CD} 3-\mathrm{CD} 27+$ cells were IFN- $\gamma$-producing cells (Figure $3 \mathbf{e}$ ) in the lungs of M. $t b$-infected CD45.1-recipient mice. After 30 days, the number of CD 45.2 cells were $6.3 \pm 0.7 \%$ ( 35 -fold increase 
a

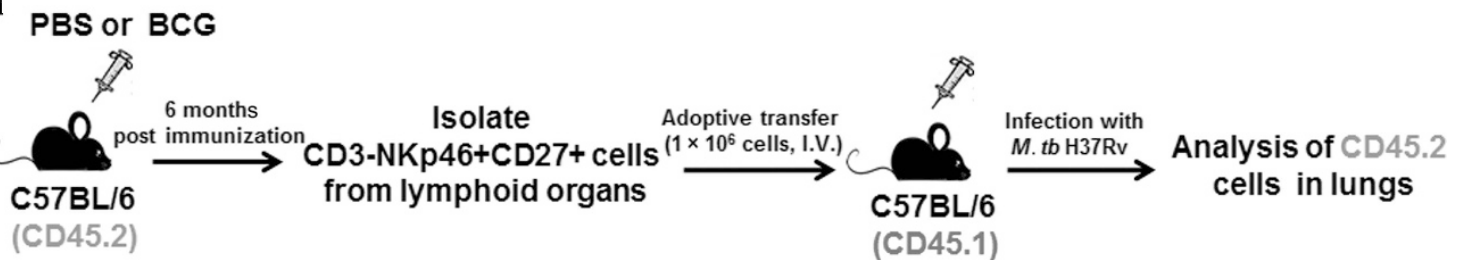

b
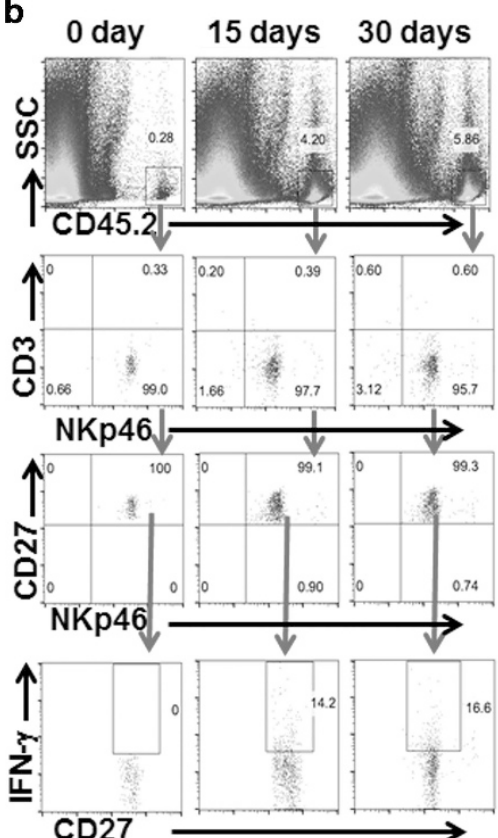

c

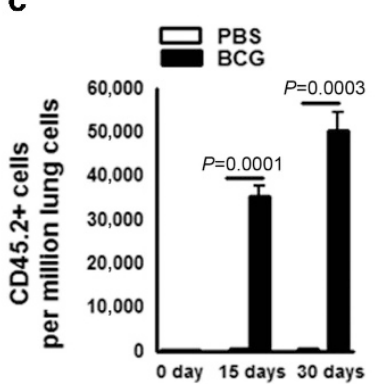

e

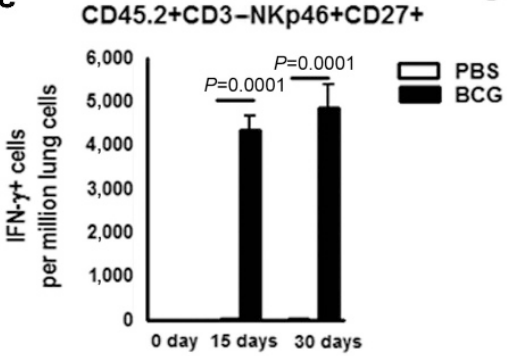

d

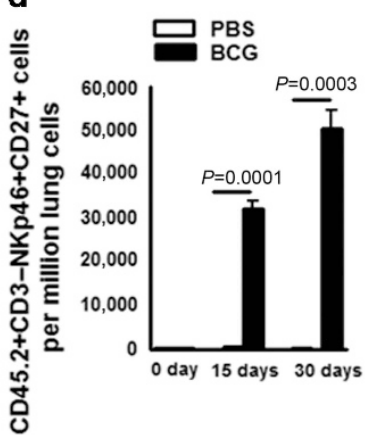

Figure 3 Memory-like natural killer (NK) cells proliferate and produce interferon-gamma (IFN- $\gamma$ ) in M. tb-infected mice. C57BL/6 (CD45.2 + congenic) mice were given $100 \mu \mathrm{l}$ phosphate-buffered saline (PBS) or immunized subcutaneously with $10^{6}$ colony-forming unit (CFU) of Bacille Calmette-Guérin $(B C G)$ in $100 \mu$ IPBS. Six months after vaccination, CD3 - NKp46 + CD27 + NK cells were isolated from pooled spleens and peripheral lymph node cells. A total of $1 \times 10^{6}$ cells were adoptively transferred to CD45.1 mice (five mice per group) through tail-vein injection 10 days before infection with $M$. tb H37Rv. (a) Schematic representation of the adoptive transfer experiment. (b) A representative flow cytometry plot is shown (CD45.2 + cells from BCG vaccinated mice). Gating strategy to identify NK cells was similar to Figure 1. (c) Absolute number of adoptively transferred CD45.2 + NK cells in lungs were determined at day 0,15 , and 30 after infection. (d) Absolute number of adoptively transferred CD45.2 + NKp46 + CD27 + NK cells in lungs were determined at day 0,15 , and 30 after infection and (e) absolute number of adoptively transferred CD45.2 + NKp46 + CD27 + IFN- $\gamma+$ NK cells in lungs were determined at day 0,15 , and 30 after infection. Mean values and s.e.'s are shown. Data are representative of two independent experiments.

compared with CD45.2 cells from PBS-treated mice, $63,520 \pm 3,164$ vs. $378.7 \pm 87.61$ cells per million lung cells, $P=0.0003$, Figure $3 \mathbf{c}$ and $\mathbf{d}$ ), and out of these, $15.7 \pm 2.6 \%$ $\mathrm{CD} 45.2+\mathrm{NKp} 46+\mathrm{CD} 3-\mathrm{CD} 27+$ cells was IFN- $\gamma$-producing cells (Figure 3e) in the lungs of $M$. $t b$-infected CD45.1-recipient mice. Our findings suggest CD3 - NKp46 + CD27 + NK cells from BCG-vaccinated mice proliferate and produce IFN- $\gamma$ upon challenge with $M . t b$.

\section{Memory-like NK cells protect mice from $\boldsymbol{M}$. $\boldsymbol{t}$ b infection}

Next, we determined whether adoptively transferred CD3 $\mathrm{NKp} 46+\mathrm{CD} 27+$ cells protect mice against $M$. $t b$ infection. C57BL/6 mice were vaccinated with BCG or treated with PBS. After 30 days, cells were pooled from the spleen and lymph nodes, and CD3 - NKp46 + CD27 + and CD3 - NKp46 + CD27 cells were isolated and adoptively transferred to naive $\mathrm{C} 57 \mathrm{BL} / 6$ mice at the time of infection with $M$. $t b \mathrm{H} 37 \mathrm{Rv}$. Adoptive transfer of CD3 - NKp46 + CD27 + cells from BCG-vaccinated mice reduced the bacterial burden in lungs by $\sim 60 \%\left(0.8 \pm 0.04 \times 10^{6}\right.$ to $0.3 \pm 0.05 \times 10^{6}, P=0.0001$, Figure $\left.4 a\right)$. In contrast adoptive transfer of CD3 - NKp46 + CD27 - cells from BCG-vaccinated mice or CD3 - NKp46 + CD27 + cells from PBS-treated mice had no effect on lung CFU (Figure 4a).

In Supplementary Figure S1D, 3 months after BCG vaccination, we found the expansion of CD3 - NKp46+CD27+ KLRG1 + cells. We also determined the functional capacity of CD3 - NKp46 + CD27 + KLRG1 + NK cells to restrict $M . t b$ growth in the lungs of infected mice. This experiment was performed same as the above except that CD3 - NKp46+ $\mathrm{CD} 27+\mathrm{KLRG} 1+$ and CD3 - NKp46 + CD27 + KLRG1 cells were isolated 3 months after BCG vaccination or PBS treatment. Adoptive transfer of CD3 - NKp46+CD27+ KLRG1 + cells from 3 months BCG-vaccinated mice reduced lung CFU from $1.1 \pm 0.14 \times 10^{6}$ to $0.12 \pm 0.02 \times 10^{6}$ (a $\log$ reduction, $P=0.002$, Figure $4 \mathbf{b})$. However, adoptive transfer of CD3 - NKp46 + CD27 + KLRG1 - cells marginally reduced bacterial burden $\left(1.1 \pm 0.14 \times 10^{6}\right.$ to $0.48 \pm 0.05 \times 10^{6}$ $P=0.02$, Figure $4 \mathbf{b}$ ). 
a
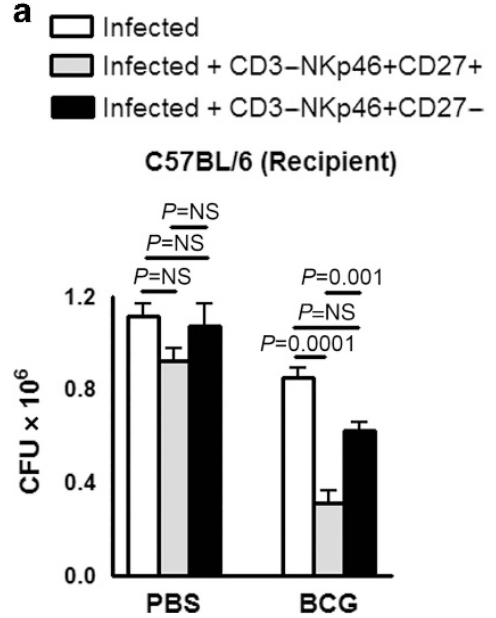

b
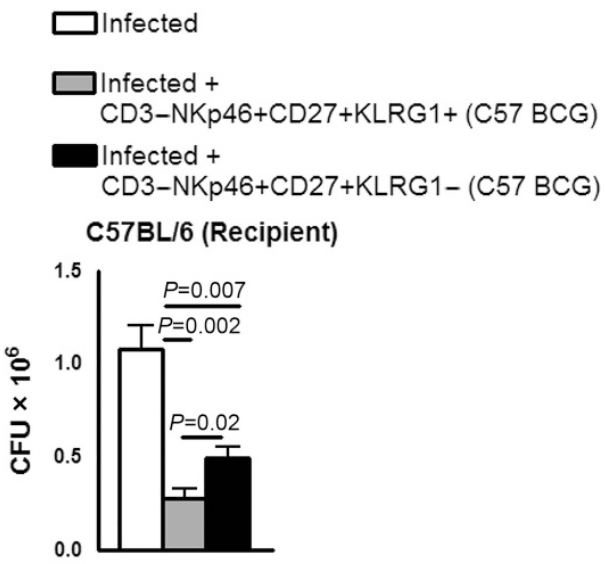

Figure 4 CD3 - NKp46 + CD27 + and CD3 - NKp46 + CD27 + KLRG1 + natural killer (NK) cells protects mice from M. tb infection. (a) Wild-type C57BL/6 mice (five mice per group) were immunized subcutaneously with $10^{6}$ colony-forming unit of Bacille Calmette-Guérin (BCG) in $100 \mu$ l of phosphate-buffered saline (PBS) or treated with PBS. After 1 month, CD3 - NKp46 + CD27 + or CD3 - NKp46 + CD27 - NK cells from pooled spleens and peripheral lymph node cells were isolated and adoptively transferred $\left(1 \times 10^{6}\right.$ cells once on day 0 of infection) to $M$. tb $\mathrm{H} 37 \mathrm{Rv}$-infected C57BL/ 6 mice. (b) The same experiment was performed as in a, except that $M$. tb-infected wild-type mice received CD3 $-\mathrm{NKp} 46+\mathrm{CD} 27+\mathrm{KLRG} 1+$ or CD3 - NKp46 + CD27 + KLRG1 - NK cells from three months BCG-vaccinated C57BL/6 mice. Infected mice in both panels were killed 30 days post infection, and lung bacterial burden was measured. Mean values and s.e.'s are shown. Data are representative of two independent experiments.

\section{Expansion and protection of memory-like NK cells depends on IL-21 production}

To determine the mechanisms involved in the expansion of memory-like NK cells in response to $M$. $t b$, we first asked whether antigen-presenting cells alone are sufficient for the expansion of CD3 - NKp46 + CD27 + cells. We cultured CD3 - NKp46 + cells and autologous peritoneal macrophages from BCG-vaccinated mice in medium alone or with Ag85. After 5 days, Ag85 did not expand CD3 - NKp46 + CD27 + cells $\left(12,930 \pm 2,076\right.$ vs. $11,300 \pm 830.2$ cells per $10^{6}$ pooled NK cells, $P=$ nonsignificant, Figure 5 a), suggesting that the expansion of memory-like NK cells requires help from other cell populations. We next determined whether cytokines produced by activated $\mathrm{T}$ cells contribute to the expansion of memory-like NK cells. Spleen and peripheral lymph node cells from BCG-vaccinated mice (one month) were isolated, pooled, and cultured, with or without Ag85, and in the presence or absence of neutralizing antibodies to IL-4, IL-7, IL-17, and IL-21. These cytokines are known to have an important role in the expansion of memory $\mathrm{T}$ cells during infection with intracellular pathogens. Ag85-dependent expansion of CD3 - NKp46 + CD27 + cells was not affected by the neutralization of IL-4, IL-7, and IL-17. In contrast, anti-IL-21 antibody significantly inhibited Ag85-dependent expansion of CD3 - NKp46 + CD27 + (Figure 5b) and CD3 - NKp46 + CD27 + KLRG1 + cells (Supplementary Figure S3A).

To further confirm that the expansion of memory-like $\mathrm{CD} 27+\mathrm{NK}$ cells is due to IL-21, we used IL-21 short interfering RNA (siRNA). Spleen and peripheral lymph node cells from BCG-vaccinated mice (3 months after vaccination) were isolated, pooled, treated with scrambled siRNA or IL-21 siRNA, and cultured with Ag85. After 5 days, expansion of $\mathrm{CD} 3-\mathrm{NKp} 46+\mathrm{CD} 27+$ cells was quantified by flow cytometry. IL-21 siRNA inhibited IL-21 messenger RNA (mRNA) expression by $70-80 \%$, as quantified by real-time PCR (Supplementary Figure S3B). In five BCG-vaccinated mice, IL-21 siRNA abrogated Ag85-dependent expansion of $\mathrm{CD} 3-\mathrm{NKp} 46+\mathrm{CD} 27+$ cells, reducing levels to those comparable to unstimulated cells (Figure 5c). In contrast, scrambled siRNA had no effect $\left(1,675 \pm 147.7\right.$ cells per $10^{6}$ pooled cells for scrambled siRNA vs. $1,002 \pm 90.91$ cells per $10^{6}$ pooled cells for IL-21 siRNA, $P=0.009$, Figure 5c).

As an additional means to determine the role of IL-21 and IL-21R signaling pathways in expansion of memory-like NK cells after BCG vaccination, we vaccinated IL-21 receptor $(6 \mathrm{NJ}$ background) and IL-21 (C57BL/6 background) knockout mice and their control wild-type mice. After 1 month, spleen and peripheral lymph node cells were isolated, pooled, and cultured with Ag85. After 5 days, in BCG-vaccinated IL-21 and IL-21R knockout mice, CD3 - NKp46 + CD27 + cells did not expand in response to Ag85 (Figure 5d and e, respectively). In contrast, in BCG-vaccinated wild-type mice, CD3 - NKp46 + CD27 + cells significantly expanded in response to Ag85 (744.0 \pm 52.12 to $3,377 \pm 551.6$ cells per $10^{6}$ pooled cells, $P=0.003$, Figure $5 \mathbf{d}$ and $\mathbf{e})$. These results provide additional evidence that IL-21 is required for the expansion of CD3 - NKp46+ $\mathrm{CD} 27+$ cells in mice.

The data above suggest BCG vaccination primes Ag-specific T-cell activation to release IL-21, which can non-specifically expand NK cells. We determine whether the above expansion of memory-like NK cells requires prior BCG vaccination or IL-21 and antigen are sufficient. We cultured pooled spleen and peripheral lymph node cells from PBS-treated mice with recombinant IL-21 and Ag85. Under these conditions, Ag85 did not expand CD3 - NKp46 + CD27 + cells, with or without recombinant IL-21 (Supplementary Figure S3C), suggesting 

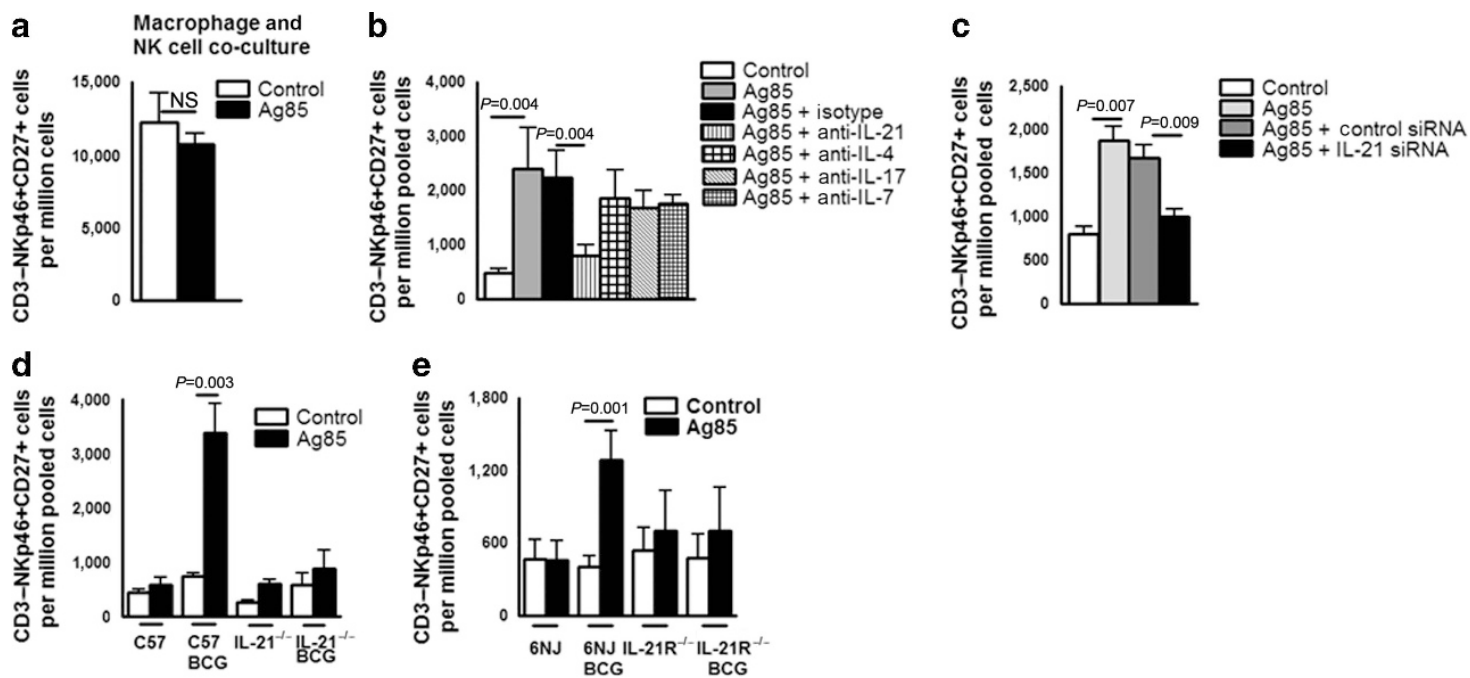

Figure 5 Expansion of memory-like natural killer (NK) cells in Bacille Calmette-Guérin (BCG)-vaccinated mice depends on interkeukin 21 (IL-21). C57BL/6 mice were treated with phosphate-buffered saline (PBS) or immunized subcutaneously with $10^{6}$ colony-forming unit (CFU) of BCG in $100 \mu$ l of PBS. One month after vaccination, spleen and peripheral lymph node cells were pooled. (a) CD3 - NK cells were isolated and cultured with peritoneal macrophages, with or without Ag85. (b) Pooled cells were cultured with or without Ag85, in the presence of isotype-matched control antibodies or antibodies to IL-4, IL-7, IL-17, or IL-21. (c) Pooled cells from 3 months BCG-vaccinated C57BL/6 mice were transfected with either IL-21 or scrambled siRNA (control siRNA) and cultured with or without Ag85. (d) Pooled cells from 1 month BCG-vaccinated IL-21 knockout and respective control mice were cultured with or without Ag85. (e) Pooled cells from 1 month BCG-vaccinated IL-21R knockout and respective control mice were cultured with or without Ag85. In all panels, after 5 days, the expansion of CD3 - NKp46 + CD27 + cells was measured by flow cytometry. Mean values and s.e.'s are shown. Data are representative of two independent experiments.

that BCG vaccination induces development of memory-like CD27 + NK cells.

\section{IL-21 is required at the time of BCG vaccination for the generation of memory-like NK cells}

IL-21 is produced by T cells and Rag2 knockout mice do not have functional T cells. To determine whether IL-21 is required at the time of vaccination for the development of memory-like NK cells that respond to mycobacterial antigens, we vaccinated Rag2 knockout mice with BCG or treated with PBS as a control. Some BCG-vaccinated mice were given recombinant IL-21 at the time of vaccination. After 1 month, pooled spleen and peripheral lymph node cells from PBS-treated, BCG-vaccinated, and BCG-vaccinated plus recombinant IL-21-treated Rag2 knockout mice were cultured with $M$. tb Ag85. After 5 days, in PBS and BCG-vaccinated Rag2 knockout mice, CD3 $\mathrm{NKp} 46+\mathrm{CD} 27$ + cells were unable to expand in response to Ag85 alone (Figure 6a). In contrast, in response to Ag85, CD3 - NKp46 + CD27 + cells significantly expanded in BCG-vaccinated Rag2 knockout mice that received recombinant IL-21 $\left(1,122 \pm 89.57\right.$ vs. $3,759 \pm 622.5$ cells per $10^{6}$ pooled cells, $P=0.005$, Figure $6 \mathbf{a}$ ).

We also determined whether CD3 - NKp46 + CD27 + cells from BCG-vaccinated Rag2 knockout mice that received recombinant IL-21 inhibits $M$. $t b$ growth in naive C57BL/6 mice. After 1 month, CD3 - NKp46 + CD27 + cells from pooled spleen and peripheral lymph node cells from BCGvaccinated and BCG-vaccinated Rag2 knockout mice that received recombinant IL-21 were isolated. The above isolated cells were adoptively transferred to wild-type C57BL/6 mice at the time of $M$. tb infection. Adoptive transfer of CD3 $\mathrm{NKp} 46+\mathrm{CD} 27+$ cells from BCG-vaccinated, IL-21-treated mice markedly reduced CFU $\left(0.8 \pm 0.1 \times 10^{6}\right.$ to $0.26 \pm$ $0.02 \times 10^{6}, P=0.0007$, Figure $\left.6 \mathbf{b}\right)$. In contrast, adoptive transfer of CD3 - NKp46 + CD27 + cells from BCG-vaccinated Rag2 mice that did not receive IL-21 had no effect on CFU $\left(0.8 \pm 0.1 \times 10^{6} \quad\right.$ to $0.58 \pm 0.09 \times 10^{6}, \quad P=$ nonsignificant, Figure 6b). Our results also confirms that CD3 - NKp46+ CD27 + cell-mediated inhibition of $M$. tb growth in Figure 4 is not due to contaminating T-cell population.

\section{Memory-like NK cells enhance cytokine and anti-microbial peptide expression in $\boldsymbol{M}$. $\boldsymbol{t} \boldsymbol{b}$-infected mice lungs}

To determine the mechanism(s) involved in the control of $M$. $t b$ infection by CD3 - NKp $46+\mathrm{CD} 27+\mathrm{NK}$ cells in the lungs of infected mice, we measured cytokine and anti-microbial peptide expression in $M$. $t b$-infected mice lungs after adoptive transfer of $\mathrm{CD} 3-\mathrm{NKp} 46+\mathrm{CD} 27+$ or $\mathrm{CD} 3-\mathrm{NKp} 46+\mathrm{CD} 27-\mathrm{NK}$ cells. C57BL/6 mice were vaccinated with BCG. After 30 days, CD3 - NKp46 + CD27 + and CD3 - NKp46 + CD27 - cells from the spleen and lymph nodes were isolated and adoptively transferred to C57BL/6 mice at the time of infection with H37Rv. Adoptive transfer of $\mathrm{CD} 3-\mathrm{NKp} 46+\mathrm{CD} 27+$ cells significantly enhanced IFN- $\gamma$, TNF- $\alpha$, IL- $1 \beta$, IL- 12 , and $\beta$-defensin mRNA in the lungs of recipient mice, whereas adoptive transfer of CD3 - NKp46 + CD27 - cells had no effect (Supplementary Figure S4). Adoptive transfer of CD3-NKp46+ $\mathrm{CD} 27+$ and CD3 - NKp46 + CD27 - cells had no effect on the expression of IL-15 and IL-18 (Supplementary Figure S4) expression in $M$. $t b$-infected mice lungs. 

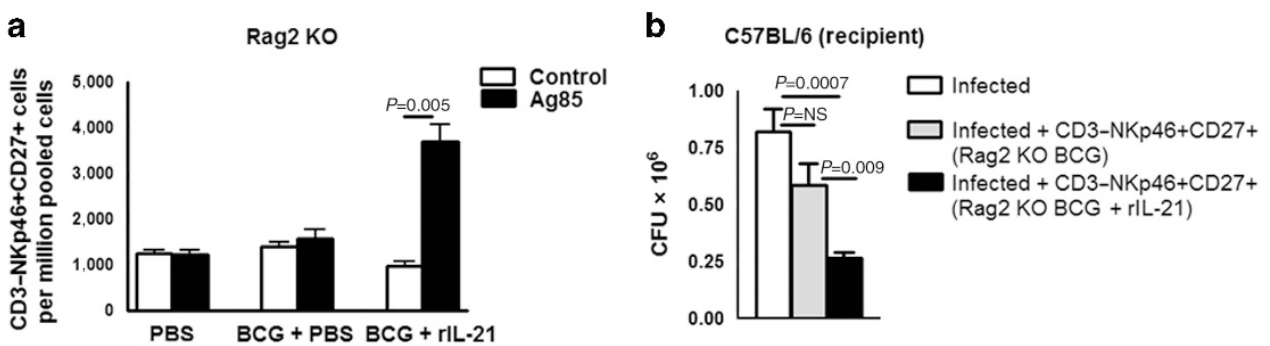

Figure 6 Interkeukin 21 (IL-21) is required at the time of Bacille Calmette-Guérin (BCG) vaccination for the generation of memory-like natural killer cells (NK) cells. C57BL/6 (Rag2 knockout) mice were treated with phosphate-buffered saline (PBS) or immunized subcutaneously with $10^{6}$ colony-forming unit (CFU) of BCG in $100 \mu \mathrm{l}$ of PBS. Some of the BCG-vaccinated mice received $0.3 \mathrm{mg}$ of recombinant IL-21 or PBS through tail vein at the time of BCG vaccination. One month after vaccination, spleen and peripheral lymph node cells were pooled. (a) Pooled cells from the above groups of mice were cultured in the presence or absence of Ag85. After 5 days, the expansion of CD3 - NKp46 + CD27 + cells was determined by flow cytometry. (b) Rag2 Knockout mice (five mice per group) were immunized subcutaneously with $10^{6} \mathrm{CFU}$ of BCG and treated with or without recombinant IL-21. After 1 month, CD3 - NKp46 + CD27 + NK cells from pooled spleens and peripheral lymph node cells were isolated and adoptively transferred $\left(1 \times 10^{6}\right.$ cells once on day 0 of infection) to $M$. tb H37Rv-infected C57BL/6 mice. Lung bacterial burden was measured after 30 days. Mean values and s.e.'s are shown. Data are representative of three independent experiments.

\section{Expansion of memory-like NK cells in individuals with LTB} Persons with LTBI have a substantial degree of protective immunity against TB. To determine whether protective immunity is associated with the expansion of memory-like NK cells, we evaluated persons with or without LTBI. Peripheral blood mononuclear cells (PBMCs) from five individuals with LTBI and five individuals without LTBI were labeled with carboxyfluorescein succinimidyl ester and cultured with or without $\gamma-M$. $t b$. After 5 days, the percentages of proliferating CD3 - CD56 + CD27 + cells were measured by flow cytometry. $\gamma-M$. $t b$ significantly expanded CD3 - CD56 + CD27 + cells in LTBI + individuals but not in LTBI individuals (947.4 \pm 156.28 vs. $381.2 \pm 57.91, P=0.0006$, Figure $7 \mathbf{a}, \mathbf{b})$. In five LTBI + individuals, we found that $\gamma$-M. $t b$-expanded CD3 - CD56 + CD27 + NK cells are the major source of IFN- $\gamma$ but not the CD3 - CD $56+$ CD27 - NK cells $(13.8 \pm 2.4$ vs. $1.0 \pm 0.19, P=0.002$, Figure $7 \mathbf{a}$ and $\mathbf{c})$.

\section{Memory-like NK cells in individuals with LTBI inhibits $M$. tb growth in autologous macrophages}

To determine the effect of memory-like NK cells (CD3$\mathrm{CD} 56+\mathrm{CD} 27+$ ) on intracellular mycobacterial growth, freshly isolated PBMCs from six LTBI were cultured with $\gamma$-irradiated M. $t b$ H37Rv. After 3 days, CD3-CD56 + CD27+ and CD3 - CD56 + CD27 - cells were isolated, as outlined in the Methods section. Autologous monocyte-derived macrophages (MDMs) were generated, infected with $M . t b \mathrm{H} 37 \mathrm{Rv}$ at a multiplicity of infection (MOI) of 1:2.5, and cultured with $M$. $t b$ expanded CD3 - CD $56+$ CD27 + or CD3 - CD56 + CD27 cells. After 5 days, $8.0 \pm 0.8 \times 10^{6} \mathrm{CFUs}$ per well were present in MDMs cultured alone. Addition of CD3 - NKp46 + CD27+ cells reduced CFU to $4.3 \pm 0.2 \times 10^{6}$ ( $>45 \%$ inhibition, $P=0.01$, Figure 7d). CD3 $-\mathrm{CD} 56+\mathrm{CD} 27+\mathrm{NK}$ cells significantly reduced the bacterial burden in MDMs compared with the addition of CD3 - NKp46 + CD27 - cells (Figure 7d). This result indicates that $\mathrm{CD} 3-\mathrm{CD} 56+\mathrm{CD} 27+$ cells inhibit $M . t b$ $\mathrm{H} 37 \mathrm{Rv}$ growth in macrophages more efficiently compared with CD3 - CD56 + CD27 - cells.

\section{Expansion of memory-like NK cells in individuals with LTBI depends on IL-21}

In Supplementary Figure S1, we found the expansion of NKp46+CD27+KLRG1 + cells in BCG-vaccinated mice. M. $t b$ antigen ESAT6 is not expressed by BCG and used to distinguish BCG vaccination vs. latent $M$. $t b$ infection. We determined the expansion of NKp46 + CD27 + KLRG1 + cells in five individuals with LTBI and five individuals without LTBI. PBMCs were cultured, with or without ESAT6, and after 5 days, the absolute number of NKp46+ CD27 + KLRG1 + cells were measured by flow cytometry. ESAT6 significantly expanded NKp46 + CD27 + KLRG1 + cells in LTBI + individuals but not in LTBI - individuals $(229.44 \pm 64.105$ vs. $561.10 \pm 141.7, P=0.004$, Supplementary Figure S5A).

We asked whether IL-21 is responsible for the expansion of NKp46 + CD27 + KLRG1 + cells in persons with LTBI. PBMCs from five individuals with LTBI were cultured with or without ESAT6. Some cells were treated with scrambled siRNA or IL-21 siRNA before culture with ESAT6. After 5 days, the expansion of NKp46+CD27 + KLRG1 + cells was determined by flow cytometry. IL-21 siRNA inhibited IL-21 mRNA expression by $70-80 \%$, as quantified by real-time PCR (Supplementary Figure S5C). IL-21 siRNA reduced ESAT6-dependent expansion of NKp46 + CD27 + KLRG1 + cells compared with scrambled siRNA (557.3 \pm 96.9 vs. $193.1 \pm 48.1 P=0.004$, Supplementary Figure S5B).

\section{DISCUSSION}

Using a mouse model of TB infection, we found that BCG vaccination induces the development of memory-like CD3 NKp46 + CD27 + NK cells. These memory-like NK cells after adoptive transfer in $M$. $t b$-infected mice were able to proliferate, produce IFN- $\gamma$, and reduce bacterial burden, providing the first evidence that these cells contribute to immunity against a bacterial pathogen. Using antibodies, siRNA, and gene-deleted mice, we found that the expansion of memory-like NK cells 


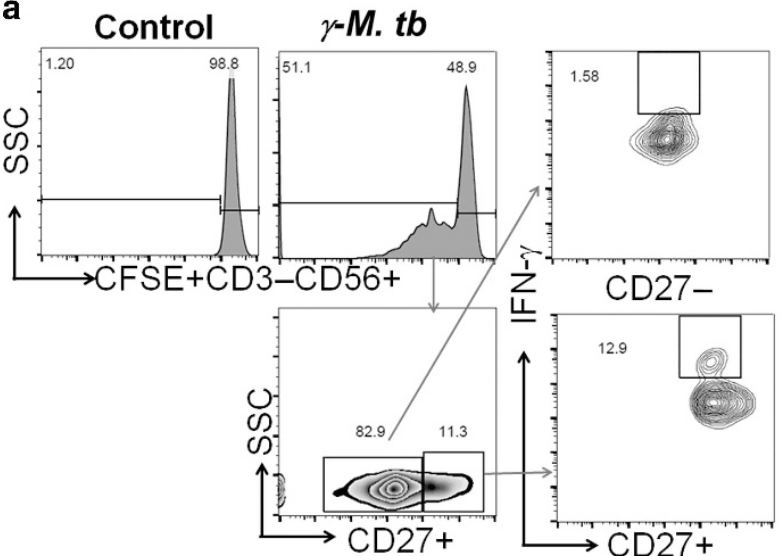

b

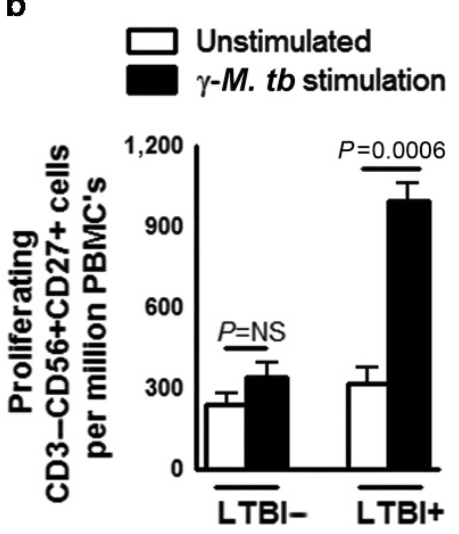

C
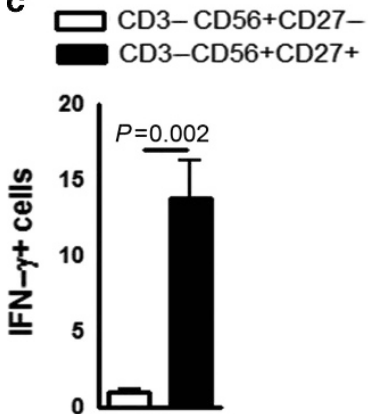

d

$\square \operatorname{CD} 14+M t b$ H37Rv

$\mathrm{CD} 14+\mathrm{Mtb} \mathrm{H} 37 \mathrm{Rv}+\mathrm{CD} 3-\mathrm{CD} 56+\mathrm{CD} 27+$ $\mathrm{CD} 14+\mathrm{Mtb} \mathrm{H} 37 \mathrm{Rv}+\mathrm{CD} 3-\mathrm{CD} 56+\mathrm{CD} 27-$

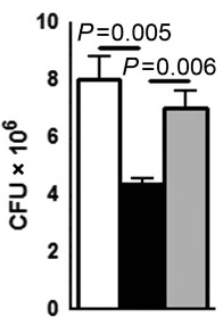

Figure 7 Expansion of memory-like natural killer (NK) cells in individuals with latent TB infection (LTBI). Peripheral blood mononuclear cells (PBMCs) from five individuals with LTBI and five individuals without LTBI were labeled with carboxyfluorescein succinimidyl ester (CFSE) and cultured, with or without $\gamma-M$. tb. After 5 days, proliferating CD3 - CD56 + CD27 + cells were measured by flow cytometry. (a) A representative flow cytometry plot is shown. NK cells were identified by sequentially gating on lymphocytic singlet population and then on CD3 - CD56 + NK cells. The events within the gated CD3 - CD56 + NK cells were analyzed for CFSE + cells and plotted in the histograms. Total PBMC CFSE + CD3 - CD56 + CD27 + NK cell numbers are shown. (b) Absolute number of proliferating CD3 - CD56 + CD27 + cells. (c) Absolute number of CD3 - CD56 + CD27+ IFN- $\gamma$ cells. Five independent experiments each time with $1 \mathrm{LTBI}+$ and one LTBI - donor was performed in a-c. (d) PBMCs from five individuals with LTBI were cultured, with or without $\gamma-M$. tb. After 3 days, CD3 - CD56 + CD27 + and CD3 - CD56 + CD27 - cells were isolated by magnetic selection. CD14 ${ }^{+}$monocytes $\left(10^{6}\right.$ per well) were isolated from fresh PBMCs and were differentiated to macrophages (MDMs) for 3 days. MDMs were infected with $M$. $t b \mathrm{H} 37 \mathrm{Rv}$ at a MOI of 1:2.5 (2.5 M. tb to one MDM). To some wells, the above isolated CD3 - CD56 + CD27 + or CD3 - CD56 + CD27 - cells were added, at a ratio of 1 NK cell:9 MDMs. Infected macrophages were cultured for 5 days, and bacterial burden was determined. Mean values and s.e.'s are shown. The data shown in (d) were performed six times, each time with PBMCs obtained from one LTBI + donor. ${ }^{\star} P \leq 0.05$ and ${ }^{\star \star} P \leq 0.01$.

depends on IL-21. In healthy individuals with LTBI and protective immunity against $M$. $t b$, memory-like NK cells expanded from PBMCs in response to $M . t b$ antigen in an IL-21-dependent manner. In contrast, memory-like NK cells did not expand from PBMCs of healthy persons who were not infected with $M$. $t b$. The sum of these data demonstrate that: (1) memory-like NK cells contribute to vaccine-induced protective immunity against $M$. $t b$; (2) expansion of memory-like NK cells in humans correlates with protective immunity against $M$. $t b$; and (3) IL-21 is required for the expansion of memory-like NK cells in both humans and mice.

NK cells have a central role in innate immunity to viruses, bacteria, and parasites through the destruction of infected cells and by the secretion of cytokines that shape the adaptive immune response. ${ }^{5,10,16} \mathrm{NK}$ cells are traditionally considered as innate cells because they possess germ-line encoded receptors and lack structurally unique receptors, somatic hypermutation, and clonal expansion. However, recent studies suggest that NK cells can be long-lived and can behave like memory T cells. In a mouse model, dendritic cell-activated NK cells provided protection against B16 melanoma for up to 1 year. ${ }^{17} \mathrm{NK}$ cells undergo homeostatic proliferation in a lymphopenic environment ${ }^{18,19}$ and generate long-lived NK cells that respond to viral infection, ${ }^{20}$ suggesting that memory-like NK cells may contribute to immune defenses in viral infections and cancer. This concept is also supported by the findings that CXCR6 + liver NK cells can generate antigen-specific memory responses, ${ }^{12,21}$ mouse NK cells expressing KLRG1 can recognize viral proteins and protect mice against secondary infection $^{13,20}$, and cytokine-dependent memory NK cells protect the host against tumors. ${ }^{22}$ Chronic viral infections in mice and human increased KLRG1 expression that has been reported in virus-specific expanded NK and CD8 $+\mathrm{T}$ cells. However, limited information is available about the factors that induce memory NK cell expansion and long-term survival, and the role of memory NK cells in vaccine-induced immunity. Our current study found that memory-like NK cells expand during BCG vaccination in mice, and contribute to vaccine-induced 
protective immunity against $M$. $t b$. Furthermore, our human studies suggest that, such as T cells, memory-like NK cells can survive in the host for long periods in persons with LTBI.

In pleural fluid of patients with tuberculous pleuritis, a subpopulation of NK cells that express the memory-associated marker, CD45RO, exert robust immune responses when stimulated by IL-12. ${ }^{23}$ These cells produce IFN- $\gamma$ in response to $\mathrm{BCG},{ }^{24}$ but it is uncertain if they are memory-like NK cells and the factors that induce their development and expansion are unknown. In infections due to Leishmania major, Pneumocystis pneumoniae, and simian immunodeficiency virus, CD4 + T-cell help is essential to activate NK cells to control infection. ${ }^{25,26}$ Similarly, CD $4+$ T-cell help is required for the expansion of memory-like NK cells and for their prolonged anti-tumor effects. ${ }^{27,28}$ The above studies found that IL-2 produced by activated T cells is essential for NK cell activation. However, in P. falciparum infection, exogenous IL-2 $\left(100 \mathrm{IU} \mathrm{ml}^{-1}\right)$ in the absence of CD4 $+\mathrm{T}$ cells is insufficient to elicit memory-like IFN- $\gamma$ responses by NK cells. ${ }^{29}$ This suggests the need for additional factors produced by $\mathrm{CD} 4+\mathrm{T}$ cells for the induction and activation of memory-like NK cells. Using neutralizing antibodies, siRNA, and mice with deleted IL-21 and IL-21R genes, the current study provides evidence that IL-21 is essential for the expansion of memory-like NK cells that contribute to vaccine-induced immunity against $M$. $t b$ and is associated with protective immunity against TB in humans. Our unpublished studies indicate that antigen-stimulated $\mathrm{CD} 4+\mathrm{T}$ cells are the major source for IL-21 in the setting of $M . t b$ infection.

IL-21 is a member of the class 1 family of cytokines, which fold into a four-helix-bundle structure. ${ }^{30}$ The biological effects of IL-21 are mediated through IL-21R, which uses the common gamma chain $(\gamma c)$, as do other members of this family, including IL-2, IL-4, IL-7, IL-9, and IL-15. ${ }^{30,31}$ Activated $\mathrm{CD} 4+\mathrm{T}$ cells are the major sources for IL-21, ${ }^{30}$ which also affects the proliferation of $\mathrm{T}$ and NK cells. ${ }^{32}$ IL-21 has antitumor effects and is in phase 2 clinical trials in patients with metastatic melanoma. ${ }^{33}$ In viral infections, IL-21 contributes to the control of persistent lymphocytic choriomeningitis virus ${ }^{34}$ and improves $\mathrm{T}$ and $\mathrm{NK}$ cell function in HIV-infected persons. ${ }^{35,36}$ However, limited information is available on the role of IL-21 in $M$. $t b$ infection. Intranasal BCG vaccination provides greater protection against $M$. $t b$ than subcutaneous BCG vaccination, and is associated with the increased expression of IL-21. ${ }^{37}$ IL-21 increases the immunogenicity of a DNA vaccine encoding Ag85 $\mathrm{A}^{38}$ and this is enhanced by a cationic nanoparticle formulation. ${ }^{39}$ A recombinant mouse cytomegalovirus expressing Ag85A provides protection against $M$. $t b$, and this protective effect is abrogated by the depletion of NK cells and blockade of IL-21, ${ }^{40}$ supporting our current findings that IL-21-mediated expansion of memory-like NK cells has a significant role in vaccine-induced protective immunity to mycobacterial infection.

The molecular mechanisms that control expansion of memory-like NK cells in response to mycobacteria remain uncertain. BCG and $M$. $t b$ can directly interact with NK cells to induce effector functions such as IFN- $\gamma$ production and cytotoxicity. ${ }^{41}$ We speculate that memory-like NK cells may develop through the engagement of specific Toll-like receptors (TLRs). NK cells express TLR2, TLR3, TLR7, TLR8, and TLR9. ${ }^{41}$ TLR2 can bind to bacterial products, and TLR2 expressed by NK cells can directly recognize $M . t b .{ }^{41}$ TLR3 engagement on NK cells can directly upregulate NK cell receptor expression and TLR7 or TLR8 ligands expressed by HIV can directly activate NK cells. ${ }^{42}$ Activation of NK cells through TLR9 can also enhance NK cell function. ${ }^{43}$ The sum of these studies suggests that early interaction between TLRs on NK cells and BCG may induce the development of memory-like NK cells. During $M$. $t b$ infection after BCG vaccination, some memory-like NK cells may interact with $M$. tb, through receptors such as CD27, and expand to effector NK cells. CD27 is a member of the TNF receptor super-family and is essential for the generation and maintenance of long-term T-cell immunity. ${ }^{44} \mathrm{CD} 27$ is also associated with priming of NK cells in response to microbial ligands, ${ }^{45}$ and $\mathrm{CD} 27^{\text {high }}$ splenic NK cells display greater effector function than CD27cells. ${ }^{46,47}$ CD27-deficient mice show normal NK cell differentiation but impaired function upon stimulation. ${ }^{48}$

In summary, using a mouse model, we found that vaccination with BCG induces expansion of memory-like NK cells that contribute to protection against subsequent $M$. $t b$ infection. Memory-like NK cells also expand in healthy persons with LTBI, suggesting that their expansion correlates with protective immunity. Expansion of memory-like NK cells in mice and humans depends on IL-21. Our work provides the first evidence that memory-like NK cells contribute to the efficacy of vaccination against microbial challenge. These findings are important for the development of improved vaccines against $\mathrm{TB}$, can facilitate the development of interventions to prevent progression of LTBI to TB, and may be relevant to the protection against other intracellular pathogens.

\section{METHODS}

Animals. All animal studies were performed on specific pathogen-free 6-8-week-old female mice according to institutional guidelines. C57BL/6 (CD45.1 and CD45.2 congenic strains), Rag2 knockout, C57BL/6 NJ (6NJ), and IL-21R were from Jackson Laboratory (Bar Harbor, ME). IL-21 knockout mice were provided by Dr. Roza Nurieva, University of Texas M. D. Anderson Cancer Center, Houston, Texas, USA.

Patient population. After obtaining written informed consent, blood was obtained from 12 healthy persons with positive QuantiFERON-TB Gold tests, indicative of LTBI, and 12 healthy persons with negative QuantiFERON-TB Gold tests. All subjects were 18-65 years old. Individuals with or without LTBI did not have a history of TB or HIV infection, and were not receiving therapy with immunosuppressive drugs.

Ethics statement. The Institutional Animal Care and Use Committee of the University of Texas Health Science Center at Tyler approved all the protocols. All animal procedures involving the care and use of mice were in accordance with the guidelines of NIH/Office of Laboratory Animal Welfare. All human studies were approved by the Institutional Review Board of the University of Texas Health Science Center at Tyler (protocol\#889). 
Antibodies and other reagents. For flow cytometry, we used fluorescein isothiocyanate anti-CD3, PE anti-CD27, PE/Cy7 antiNKp46, FITC anti-CD8, PE anti-CD11b, PE anti-CD56, and allophycocyanin KLRG1 (all from BioLegend, San Diego, CA). For neutralization, we used monoclonal antibodies to IL-4, IL-7, IL-17, IL-21, or isotype-matched control antibody (eBioscience, San Diego, CA). Recombinant mouse IL-21 was obtained from eBioscience. We used $\gamma$-irradiated $M . t b \operatorname{H} 37 \mathrm{Rv}(\gamma-M . t b)$, ESAT6, and Ag85a (all from BEI Resources), and the BCG Tice strain (Organon USA Inc., NJ).

Flow cytometry. Surface and intracellular staining was performed using our published methods. ${ }^{9}$

BCG vaccination and aerosol infection with $\boldsymbol{M}$. $\boldsymbol{t b}$ H37Rv. C57BL/6 mice were immunized subcutaneously with $10^{6}$ CFU of BCG in $100 \mu 1$ of PBS, or with PBS alone. In some experiments, Rag2 knockout mice were given $0.3 \mathrm{mg}$ of recombinant IL-21 or PBS intravenously at the time of BCG vaccination. One, three, and six months after vaccination, mice were infected with 50-100 CFU of $M$. $t b \mathrm{H} 37 \mathrm{Rv}$ in an aerosol exposure chamber, using our published methods. ${ }^{9,49}$

Cell isolation and adoptive transfer of NK cells. NK cells from pooled spleens and peripheral lymph nodes of 1 or 3 or 6 months BCGvaccinated or PBS-treated mice were isolated by negative immunomagnetic selection (Miltenyi Biotec, Auburn, CA). From the negatively selected NK cells (>97\% CD3 - NKp46+), CD27+ cells were isolated by positive selection, and $\mathrm{CD} 3-\mathrm{NKp} 46+\mathrm{CD} 27+$ and CD3 - NKp46 + CD27 - cells were used for adoptive transfer. To isolate CD3 - NKp46 + CD27 + KLRG1 + cells, the above isolated $\mathrm{CD} 3-\mathrm{NKp} 46+\mathrm{CD} 27+$ cells were stained using PE-conjugated anti-KLRG1 antibody and then sorted using anti-PE MultiSort kit (Miltenyi Biotec, Auburn, CA) according to the manufacturer's instruction. In some experiments, CD3 - CD56 + cells were isolated from human PBMCs by negative immunomagnetic selection (Miltenyi Biotec). From the negatively selected NK cells (>97\% CD3$\mathrm{NKp} 46+$ ), CD27 + cells were isolated by positive selection. Purity of the isolated cells was $>96 \%$ as determined by flow cytometry. In the purified NK cell population, $<0.1 \%$ of the cells were T and B cells. One million $\mathrm{CD} 3-\mathrm{NKp} 46+\mathrm{CD} 27+, \mathrm{CD} 3-\mathrm{NKp} 46+\mathrm{CD} 27-$, $\mathrm{CD} 3-\mathrm{NKp} 46+\mathrm{CD} 27+\mathrm{KLRG} 1+$, or $\mathrm{CD} 3-\mathrm{NKp} 46+\mathrm{CD} 27+$ KLRG1 - cells were adoptively transferred to mice through the tailvein injection, $30 \mathrm{~min}$ before $M$. $t b$ infection.

Culture of lung, spleen, and lymph node cells. BCG-vaccinated mice, uninfected or infected with $M$. $t b \mathrm{H} 37 \mathrm{Rv}$, were killed, and cells from the lungs, spleens and peripheral lymph nodes were cultured in 24 -well plates at $2 \times 10^{6}$ cells per well in RPMI-1640 containing penicillin (Life Technologies, Carlsbad, CA) and 10\% heat-inactivated fetal calf serum (FCS), with or without $\gamma$-irradiated $\mathrm{H} 37 \mathrm{Rv}$ $\left(10 \mu \mathrm{g} \mathrm{ml}^{-1}\right)$ or $\mathrm{Ag} 85 \mathrm{a}\left(3 \mu \mathrm{g} \mathrm{ml}^{-1}\right)$ at $37^{\circ} \mathrm{C}$ and $5 \% \mathrm{CO}_{2}$. For cell proliferation experiments, cells were cultured in the presence of carboxyfluorescein succinimidyl ester $(5 \mu \mathrm{M})$. After 5 days, culture supernatants were collected to determine cytokine levels, and the expansion of CD3 - NKp46+CD27 + or CD3 - NKp46 + CD27 + IFN $-\gamma+$ cells was measured by immunolabeling and flow cytometry. For cytokine neutralization experiments, $10 \mu \mathrm{g} \mathrm{ml}^{-1}$ neutralizing antibody to IL-17, IL-2, IL-21, and IL-4 were added to the cultures. For intracellular staining, freshly isolated lung cells were immunostained to determine IFN- $\gamma$-positive $\mathrm{CD} 3-\mathrm{NKp} 46+\mathrm{CD} 27+, \mathrm{CD} 3-$ $\mathrm{NKp} 46+\mathrm{CD} 27-$, CD3 - NKp46 + CD27 + KLRG1 +, or CD3 $\mathrm{NKp} 46+\mathrm{CD} 27+\mathrm{KLRG} 1-$ cells.

Culturing of mouse peritoneal exudate macrophages and NK cells. Peritoneal exudate macrophages were isolated as previously described. ${ }^{50}$ In some experiments, peritoneal exudate macrophages and purified NK cells were cultured at the ratio of 1:5 in 24-well plates containing RPMI-1640 supplemented with penicillin (Life Technologies) and 10\% heat-inactivated FCS, with or without Ag85a $\left(3 \mu \mathrm{g} \mathrm{ml}^{-1}\right)$ at $37^{\circ} \mathrm{C}$ and $5 \% \mathrm{CO}_{2}$. After 5 days, IFN- $\gamma$-positive $\mathrm{CD} 3-\mathrm{NKp} 46+\mathrm{CD} 27+, \quad \mathrm{CD} 3-\mathrm{NKp} 46+\mathrm{CD} 27-, \quad \mathrm{CD} 3-$ $\mathrm{NKp} 46+\mathrm{CD} 27$ + KLRG1 + , or CD3 - NKp46 + CD27 + KLRG1 cells were determined by flow cytometry.

Isolation and culture of PBMCs. PBMCs were isolated by differential centrifugation over Ficoll-Paque (Amersham Pharmacia Biotech, Pittsburgh, PA). PBMCs were cultured in 12 -well plates at $2 \times 10^{6}$ cells per well in RPMI-1640 containing 10\% heat-inactivated human serum, and ESAT6 $\left(5 \mu \mathrm{g} \mathrm{ml}^{-1}\right)$ at $37^{\circ} \mathrm{C}$. In some experiments, cells were cultured in the presence of carboxyfluorescein succinimidyl ester $(5 \mu \mathrm{M})$. After 5 days, the expansion of CD3 - CD $56+\mathrm{CD} 27+$, $\mathrm{CD} 3-\mathrm{CD} 56+\mathrm{CD} 27-, \mathrm{CD} 3-\mathrm{CD} 56+\mathrm{CD} 27+\mathrm{IFN}-\gamma+, \mathrm{CD} 3-$ $\mathrm{CD} 56+\mathrm{CD} 27+\mathrm{IFN}-\gamma-, \mathrm{CD} 3-\mathrm{NKp} 46+\mathrm{CD} 27+\mathrm{KLRG} 1+$, and $\mathrm{CD} 3-\mathrm{NKp} 46+\mathrm{CD} 27+\mathrm{KLRG} 1-$ cells were determined by immunolabeling and flow cytometry.

Real-time PCR for the quantification of IL-21, IL-1 $\beta$, IL-12, IL-15, IL-18, IFN- $\gamma$, TNF- $\alpha$ and beta-defensin mRNA. The above gene expression in $M . t b$-infected mice lungs and spleens was performed as previously described. ${ }^{9}$ Mouse primer sequences were given in Supplementary Table S1.

siRNA. Freshly isolated human PBMCs or mouse spleen cells were transfected with siRNA for IL-21 or control siRNA, using transfection reagents (all from Santa Cruz Biotechnology, Dallas, TX). The efficiency of siRNA knockdown was measured by real-time PCR of human or mouse IL-21 mRNA expression. In brief, $10^{6}$ cells were resuspended in $500 \mu \mathrm{l}$ of transfection medium and transfected with siRNA ( 6 pmol). After $6 \mathrm{~h}$, an additional $500 \mu \mathrm{l}$ of $2 \times$ RPMI- 1640 complete medium was added, and cells were cultured overnight in a 24 -well plate. The next day, cells were washed and stimulated with either Ag85a or ESAT6, or kept in medium alone as a control. Expansion of memory-like NK cell subpopulations was determined after 5 days.

Infection of human macrophages with $M$. $t b$, and coculture with autologous NK cells. CD14 ${ }^{+}$monocytes $\left(10^{6}\right.$ per well $)$ were plated in 12 -well plates in $1 \mathrm{ml}$ of antibiotic-free RPMI-1640 containing $10 \%$ heat-inactivated human serum, and incubated at $37^{\circ} \mathrm{C}$ in a humidified $5 \% \mathrm{CO}_{2}$ atmosphere for 3 days to differentiate into macrophages. At the same time, PBMCs were cultured with $\gamma-M$. $t b$ for 3 days, and $\mathrm{CD} 3-\mathrm{CD} 56+\mathrm{CD} 27+$ or $\mathrm{CD} 3-\mathrm{CD} 56+\mathrm{CD} 27-$ cells were isolated, as outlined above. MDMs were infected with $M$. $t b \mathrm{H} 37 \mathrm{Rv}$ at a MOI of 1:2.5 (2.5 M. tb to one MDM), incubated for $2 \mathrm{~h}$ at $37^{\circ} \mathrm{C}$, washed to remove extracellular bacilli, and cultured in RPMI- 1640 containing $10 \%$ heat-inactivated human serum. To some wells, $\mathrm{CD} 3-\mathrm{CD} 56+\mathrm{CD} 27+$ or $\mathrm{CD} 3-\mathrm{CD} 56+\mathrm{CD} 27-$ cells were added, at a ratio of $1 \mathrm{NK}$ cell:9 MDMs. Infected macrophages were cocultured for 5 days, at which point macrophage viability was $>90 \%$. The supernatant was aspirated, and macrophages were lysed. The supernatant was centrifuged to pellet bacteria, and the pellets were added to the cell lysates. Bacterial suspensions were ultrasonically dispersed, serially diluted, and plated in triplicate on 7H10 agar. The number of colonies was counted after 3 weeks.

Statistical analysis. Results are shown as the mean \pm s.e. For data that were normally distributed, comparisons between groups were performed by a paired or unpaired $t$-test, as appropriate. For data that were not normally distributed, the Wilcoxon rank-sum test was used.

SUPPLEMENTARY MATERIAL is linked to the online version of the paper at http://www.nature.com/mi

\section{ACKNOWLEDGMENTS}

We thank Dr Lewis Lanier for his helpful discussion. This work was supported by grants from the National Institutes of Health (Al054629, Al073612 and A1085135 to R.V.), the Cain Foundation for Infectious 
Disease Research, CRDF Global, and the Department of Pulmonary Immunology.

\section{DISCLOSURE}

The authors declared no conflict of interest.

Official journal of the Society for Mucosal Immunology

\section{REFERENCES}

1. Zumla, A. et al. The WHO 2014 global tuberculosis report-further to go. Lancet Glob. Health 3, e10-e12 (2015).

2. Manabe, Y.C. \& Bishai, W.R. Latent Mycobacterium tuberculosispersistence, patience, and winning by waiting. Nat. Med. 6 , 1327-1329 (2000).

3. Flynn, J.L. \& Chan, J. Immunology of tuberculosis. Annu. Rev. Immunol. 19, 93-129 (2001).

4. Flynn, J.L. et al. An essential role for interferon gamma in resistance to Mycobacterium tuberculosis infection. J. Exp. Med. 178, 2249-2254 (1993).

5. Tay, C.H., Szomolanyi-Tsuda, E. \& Welsh, R.M. Control of infections by NK cells. Curr. Top. Microbiol. Immunol. 230, 193-220 (1998).

6. Vankayalapati, R. et al. Role of NK cell-activating receptors and their ligands in the lysis of mononuclear phagocytes infected with an intracellular bacterium. J. Immunol. 175, 4611-4617 (2005).

7. Vankayalapati, R. et al. NK cells regulate CD8 + T cell effector function in response to an intracellular pathogen. J. Immunol. 172, 130-137 (2004).

8. Roy, S. et al. NK cells lyse Tregulatory cells that expand in response to an intracellular pathogen. J. Immunol. 180, 1729-1736 (2008).

9. Dhiman, R. et al. NK1.1 + cells and IL-22 regulate vaccine-induced protective immunity against challenge with Mycobacterium tuberculosis. J. Immunol. 189, 897-905 (2012).

10. Marcenaro, E., Ferranti, B., Falco, M., Moretta, L. \& Moretta, A. Human NK cells directly recognize Mycobacterium bovis via TLR2 and acquire the ability to kill monocyte-derived DC. Int. Immunol. 20, 1155-1167 (2008).

11. Schierloh, P. et al. Increased susceptibility to apoptosis of CD56dimCD16 + NK cells induces the enrichment of IFN-gammaproducing CD56bright cells in tuberculous pleurisy. J. Immunol. 175, 6852-6860 (2005).

12. Paust, S. et al. Critical role for the chemokine receptor CXCR6 in NK cellmediated antigen-specific memory of haptens and viruses. Nat Immunol 11, 1127-1135 (2010).

13. Sun, J.C., Lopez-Verges, S., Kim, C.C., DeRisi, J.L. \& Lanier, L.L. NK cells and immune 'memory'. J. Immunol. 186, 1891-1897 (2011).

14. Lopez-Vergès, S. et al. Expansion of a unique $\mathrm{CD} 57^{+} \mathrm{NKG2Chi} \mathrm{natural}$ killer cell subset during acute human cytomegalovirus infection. Proc. Natl Acad. Sci. USA 108, 14725-14732 (2011).

15. Sun, J.C. et al. Proinflammatory cytokine signaling required for the generation of natural killer cell memory. J. Exp. Med. 209, 947-954 (2012).

16. Yokoyama, W.M., Kim, S. \& French, A.R. The dynamic life of natural killer cells. Annu. Rev. Immunol. 22, 405-429 (2004).

17. Shimizu, K. \& Fujii, S. DC therapy induces long-term NK reactivity to tumors via host DC. Eur. J. Immunol. 39, 457-468 (2009).

18. Jamieson, A.M., Isnard, P., Dorfman, J.R., Coles, M.C. \& Raulet, D.H. Turnover and proliferation of NK cells in steady state and lymphopenic conditions. J. Immunol. 172, 864-870 (2004).

19. Prlic, M., Blazar, B.R., Farrar, M.A. \& Jameson, S.C. In vivo survival and homeostatic proliferation of natural killer cells. J. Exp. Med. 197, 967-976 (2003).

20. Sun, J.C., Beilke, J.N., Bezman, N.A. \& Lanier, L.L. Homeostatic proliferation generates long-lived natural killer cells that respond against viral infection. J. Exp. Med. 208, 357-368 (2011).

21. O'Leary, J.G., Goodarzi, M., Drayton, D.L. \& Andrian, U.H. von Tcell- and B cell-independent adaptive immunity mediated by natural killer cells. Nat. Immunol. 7, 507-516 (2006).

22. Cooper, M.A. et al. Cytokine-induced memory-like natural killer cells. Proc. Natl Acad. Sci. USA 106, 1915-1919 (2009).

23. Fu, X. et al. Human natural killer cells expressing the memory-associated marker CD45RO from tuberculous pleurisy respond more strongly and rapidly than $\mathrm{CD} 45 \mathrm{RO}$ - natural killer cells following stimulation with interleukin-12. Immunology 134, 41-49 (2011).

24. Fu, X., Yang, B., Lao, S., Fan, Y. \& Wu, C. Human memory-like NK cells migrating to tuberculous pleural fluid via IP-10/CXCR3 and SDF-1/CXCR4 axis produce IFN- $\gamma$ in response to Bacille Calmette Guerin. Clin. Immunol. 148, 113-123 (2013).

25. Kelly, M.N. et al. Memory CD4 + T cells are required for optimal NK cell effector functions against the opportunistic fungal pathogen Pneumocystis murina. J. Immunol. 190, 285-295 (2013).

26. Bihl, F. et al. Primed antigen-specific CD4 + T cells are required for NK cell activation in vivo upon Leishmania major infection. J. Immunol. 185, 2174-2181 (2010).

27. Leong, J.W. et al. Preactivation with IL-12, IL-15, and IL-18 induces CD25 and a functional high-affinity IL-2 receptor on human cytokine-induced memory-like natural killer cells. Biol. Blood Marrow Transplant 20, 463-473 (2014)

28. Shimizu, K., Asakura, M. \& Fujii, S. Prolonged antitumor NK cell reactivity elicited by CXCL10-expressing dendritic cells licensed by CD4OL + CD4 + memory T cells. J. Immunol. 186, 5927-5937 (2011).

29. McCall, M.B.B. et al. Memory-like IFN- $\gamma$ response by NK cells following malaria infection reveals the crucial role of T cells in NK cell activation by P. falciparum. Eur. J. Immunol. 40, 3472-3477 (2010).

30. Parrish-Novak, J. et al. Interleukin 21 and its receptor are involved in NK cell expansion and regulation of lymphocyte function. Nature 408, 57-63 (2000).

31. Habib, T., Nelson, A. \& Kaushansky, K. IL-21: a novel IL-2-family lymphokine that modulates $\mathrm{B}, \mathrm{T}$, and natural killer cell responses. J. Allergy Clin. Immunol. 112, 1033-1045 (2003).

32. Parrish-Novak, J., Foster, D.C., Holly, R.D. \& Clegg, C.H. Interleukin-21 and the $\mathrm{IL}-21$ receptor: novel effectors of NK and T cell responses. J. Leukoc. Biol. 72, 856-863 (2002).

33. Davis, I.D. et al. Clinical and biological efficacy of recombinant human interleukin-21 in patients with stage IV malignant melanoma without prior treatment: a phase lla trial. Clin. Cancer Res. 15, 2123-2129 (2009).

34. Johnson, L.D.S. \& Jameson, S.C. Immunology. A chronic need for IL-21. Science 324, 1525-1526 (2009).

35. lannello, A. et al. IL-21 enhances NK cell functions and survival in healthy and HIV-infected patients with minimal stimulation of viral replication. J. Leukoc. Biol. 87, 857-867 (2010).

36. Strbo, N. et al. IL-21 augments natural killer effector functions in chronically HIV-infected individuals. AIDS 22, 1551-1560 (2008).

37. Derrick, S.C., Kolibab, K., Yang, A. \& Morris, S.L. Intranasal administration of Mycobacterium bovis BCG induces superior protection against aerosol infection with Mycobacterium tuberculosis in mice. Clin. Vaccine Immunol 21, 1443-1451 (2014).

38. Dou, J. et al. Protection against Mycobacterium tuberculosis challenge in mice by DNA vaccine Ag85A-ESAT-6-IL-21 priming and BCG boosting. Int. J. Immunogenet. 39, 183-190 (2012).

39. Yu, F. et al. Nanoparticle-based adjuvant for enhanced protective efficacy of DNA vaccine Ag85A-ESAT-6-IL-21 against Mycobacterium tuberculosis infection. Nanomedicine 8, 1337-1344 (2012).

40. Beverley, P.C.L. et al. A novel murine cytomegalovirus vaccine vector protects against Mycobacterium tuberculosis. J. Immunol. 193, 2306-2316 (2014).

41. Chiesa, M. Della et al. Human NK cell response to pathogens. Semin. Immunol. 26, 152-160 (2014).

42. Hart, O.M., Athie-Morales, V., O'Connor, G.M. \& Gardiner, C.M. TLR7/8-mediated activation of human NK cells results in accessory cell-dependent IFN-gamma production. J. Immunol. 175, 1636-1642 (2005).

43. Sivori, S. et al. A novel KIR-associated function: evidence that CpG DNA uptake and shuttling to early endosomes is mediated by KIR3DL2. Blood 116, 1637-1647 (2010).

44. Hendriks, J. et al. CD27 is required for generation and long-term maintenance of T cell immunity. Nat. Immunol. 1, 433-440 (2000).

45. Watt, S.V., Andrews, D.M., Takeda, K., Smyth, M.J. \& Hayakawa, Y. IFN-gamma-dependent recruitment of mature CD27(high) NK cells to lymph nodes primed by dendritic cells. J. Immunol. 181, 5323-5330 (2008). 
46. Brady, J. et al. The interactions of multiple cytokines control NK cell maturation. J. Immunol. 185, 6679-6688 (2010).

47. Marquardt, N., Wilk, E., Pokoyski, C., Schmidt, R.E. \& Jacobs, R. Murine CXCR3 + CD27bright NK cells resemble the human CD56bright NK-cell population. Eur. J. Immunol. 40, 1428-1439 (2010).

48. Colvenaer, V.De. et al. CD27-deficient mice show normal NK-cell differentiation but impaired function upon stimulation. Immunol. Cell Biol. 89, 803-811 (2011).

49. Venkatasubramanian, S. et al. A rho GDP dissociation inhibitor produced by apoptotic T-cells inhibits growth of Mycobacterium tuberculosis. PLOS Pathog. 11, e1004617 (2015).

50. Zhang, X., Goncalves, R. \& Mosser, D.M. The isolation and characterization of murine macrophages. Curr. Protoc. Immunol. Chapter 14, Unit 14.1 (2008).
This work is licensed under a Creative Commons Attribution-NonCommercial-NoDerivs 4.0 International License. The images or other third party material in this article are included in the article's Creative Commons license, unless indicated otherwise in the credit line; if the material is not included under the Creative Commons license, users will need to obtain permission from the license holder to reproduce the material. To view a copy of this license, visit http://creativecommons.org/licenses/by-nc-nd/4.0/

(C) The Author(s) 2017 